\title{
Variation in Streptomycin Resistance Mechanisms in Clavibacter michiganensis
}

\author{
Qingyang Lyu, ${ }^{1,2}$ Kaihong Bai, ${ }^{1}$ Yumin Kan, ${ }^{1} \mathrm{Na}$ Jiang, ${ }^{1}$ Shree P. Thapa, ${ }^{2}$ Gitta Coaker, ${ }^{2}$ Jianqiang Li, ${ }^{1}$ and Laixin Luo ${ }^{1, \dagger}$ \\ ${ }^{1}$ Department of Plant Pathology, College of Plant Protection, China Agricultural University, Beijing, People's Republic of China \\ 2 Department of Plant Pathology, University of California, Davis, CA, U.S.A. \\ Accepted for publication 20 July 2019.
}

ABSTRACT

\begin{abstract}
Clavibacter michiganensis is the causal agent of bacterial canker of tomato, which causes significant economic losses because of the lack of resistant tomato varieties. Chemical control with streptomycin or cupric bactericides is the last defensive line in canker disease management. Streptomycin is an aminoglycoside antibiotic that inhibits protein synthesis and targets the $30 \mathrm{~S}$ ribosomal protein RpsL. Streptomycin has been used to control multiple plant bacterial diseases. However, identification and characterization of streptomycin resistance in C. michiganensis have remained unexplored. In this study, a naturally occurring C. michiganensis strain TX-0702 exhibiting spontaneous streptomycin resistance was identified, with a minimum inhibitory concentration of $128 \mu \mathrm{g} / \mathrm{ml}$. Additionally, an induced streptomycin-resistant strain BT-0505-R was generated by experimental evolution of the sensitive
\end{abstract}

C. michiganensis strain BT-0505. Genome sequencing and functional analyses were used to identify the genes conferring resistance. A point mutation at the 128th nucleotide in the rpsL gene of strain BT-0505-R is responsible for conferring streptomycin resistance. However, in TX0702, resistance is not attributed to mutation of rpsL, streptomycin inactivation enzymes, or multidrug efflux pumps. The mechanism of resistance in TX-0702 is independent of previously reported bacterial loci. Taken together, these data highlight diverse mechanisms used by a Gram-positive plant pathogenic bacterium to confer antibiotic resistance.

Keyword: bacteriology, Clavibacter michiganensis, resistance mechanism, streptomycin
Species within the genus Clavibacter are xylem-colonizing, Gram-positive bacteria. Average nucleotide identity from wholegenome analyses, DNA-DNA hybridization, and multilocus sequencing analyses have elevated six Clavibacter michiganensis subspecies to the species level (Li et al. 2018). Specific Clavibacter species can infect both monocots and dicots. Bacterial canker is one of the most destructive bacterial diseases in tomato production, causing significant yield losses worldwide (Sen et al. 2015). The causal agent of bacterial canker of tomato is $C$. michiganensis (also known as $C$. michiganensis subsp. michiganensis), and disease symptoms in the field include unilateral leaflet wilting, leaflet chlorosis/necrosis, stem cankers, "birds-eye" spots on fruit, and inhibition of plant growth (Medina-Mora et al. 2001). C. michiganensis resides in the xylem and results in browning of the vasculature and inhibition of water transport, leading to wilting symptoms (Gleason et al. 1993). In addition to seedborne infection and mechanical inoculation, $C$. michiganensis can also invade broken trichomes or hydathodes from the leaf surface, eventually localizing in tomato fruits and seeds (Chalupowicz et al. 2017; Davis et al. 1984; Tancos et al. 2013). Contaminated tomato seeds are frequently associated with disease outbreaks, leading to significant challenges with disease control (Lelis et al. 2014; Xu et al. 2010).

Researchers have attempted to identify resistant tomato germplasm, and some moderate resistant sources have been identified in

†Corresponding author: L. Luo; luolaixin@cau.edu.cn

Funding: This work was funded by National Natural Science Foundation of China grant 31571972, China Scholarship Council grant 201706350190, and California Institute of Food and Agriculture grant 1700275-047-SC.

*The $e$-Xtra logo stands for "electronic extra" and indicates that three supplementary figures and five supplementary tables are published online.

The author(s) declare no conflict of interest.

(c) 2019 The American Phytopathological Society wild Solanum species (Chang et al. 1992; Coaker et al. 2004; Poysa 1993; Sandbrink et al. 1995; Sen et al. 2013; van Heusden et al. 1999). A transgenic tomato plant expressing an endolysin gene (lys) from the phage of C. michiganensis did not exhibit bacterial wilt and canker symptoms on inoculation with C. michiganensis (Wittmann et al. 2016). However, there are still no commercial cultivars with resistance. Currently, $C$. michiganensis is controlled by using a combination of clean seeds and good horticultural practices (Fatmi et al. 1991; Gitaitis and Walcott 2007; Munkvold 2009). Copper compounds and antibiotics are the last line of defense against C. michiganensis because of the lack of additional genetic and chemical control methods. Compared with the treatment of kasugamycin and copper, streptomycin is more effective than kasugamycin but less effective than copper (de León et al. 2008). Both streptomycin and copper can reduce the population size and spread of $C$. michiganensis in the greenhouse (Hausbeck et al. 2000). However, the ability of streptomycin to limit C. michiganensis was inconsistent between independent trials and did not reduce symptoms on tomato fruits (de León et al. 2008; Hausbeck et al. 2000; Werner et al. 2002). As far as we know, the use of streptomycin as a pesticide on agricultural plants is forbidden in the European Union because of rising concerns over antibiotic resistance. In the United States, streptomycin is allowed in the management of some crop diseases, such as the treatment of huanglongbing on citrus in Florida (Wang et al. 2017). In China, streptomycin sulfate is also available and can be used to control bacterial diseases because of its low price and good effect with application rates between 100 and $150 \mathrm{~g}$ of active ingredient per hectare.

Streptomycin is an aminoglycoside compound that was first reported in 1944 as a medication for tuberculosis treatment (Schatz et al. 1944). Based on the importance of bacterial diseases in plants, streptomycin has been applied since the 1950s to control the fire blight disease in apple and pear orchards (Leben and Keitt 1954; Moller et al. 1981). Streptomycin targets the S12 protein of ribosomal $30 \mathrm{~S}$ subunit, killing the bacteria by interfering with protein synthesis (Chiou and Jones 1995). Mutations in rpsL, which 
encodes the S12 protein, causes high-level resistance to streptomycin (McManus et al. 2002). Furthermore, mutations within the $16 \mathrm{~S}$ ribosomal RNA gene (rrs) can also lead to resistance in Mycobacterium tuberculosis by interfering with the conformation of the streptomycin binding to ribosome (Finken et al. 1993; Meier et al. 1996). Other resistance mechanisms are related to enzymes and efflux pumps (Sundin and Wang 2018). In the newly established comprehensive antibiotic resistance database (CARD), there are 40 protein sequences related to streptomycin resistance, including 35 proteins capable of inactivating streptomycin. However, most of the proteins in the CARD are based on results from human bacterial pathogens (Jia et al. 2017). The molecular mechanisms responsible for streptomycin resistance in Gram-positive plant-pathogenic bacteria remain elusive.

In this study, we tested the sensitivity of $179 C$. michiganensis strains to streptomycin. Three strains exhibiting spontaneous resistance were identified. Induced resistant strains were also generated based on selective pressure. The mechanism of resistance was explored using whole-genome sequencing and complementation analyses. These results provide a greater understanding of Gram-positive bacteria antibiotic resistance.

\section{MATERIALS AND METHODS}

Isolates, media, and chemicals. The $C$. michiganensis strains used in this study are listed in Supplementary Table S1, and they are sorted by source, including geographical location and the year of isolation. One hundred and forty-seven strains were isolated from the field, and 15 strains were isolated from tomato seeds, whereas the isolation area of the remaining 17 strains is unknown (exchanged or gifted from collaborators without specific origin information). Tryptone broth with yeast (TBY) and TBY agar were formulated with $5 \mathrm{~g}$ of $\mathrm{NaCl}, 5 \mathrm{~g}$ of yeast extract, $10 \mathrm{~g}$ of tryptone, and $16 \mathrm{~g}$ of agar per liter. Streptomycin sulfate antibiotic (MW [molecular weight]: 1,457.38) was purchased from Amresco and dissolved in distilled water at serial concentrations varying from 0 to $5,000 \mu \mathrm{g} / \mathrm{ml}$.

The structure of the medium for screening is illustrated in Figure 1A. It is composed of TBY and tryptone broth with yeast medium with $100 \mu \mathrm{g} / \mathrm{ml}$ streptomycin added (TBY-S100), resulting in a gradient concentration (GC) within a single petri dish (tryptone broth with yeast-gradient concentration-streptomycin [TBY-GC-S] medium).

Screening and induction of streptomycin-resistant mutants. All 179 C. michiganensis strains were screened by spreading $100 \mu \mathrm{l}$ of a $10^{2} \mathrm{CFU} / \mathrm{ml}$ bacterial suspension on three media (TBY, TBYGC-S, and TBY-S100). Colonies were counted on the different media after incubation for 3 days at $28^{\circ} \mathrm{C}$.

The induction of a streptomycin-resistant $C$. michiganensis isolate was based on selection on media containing streptomycin. A 300- $\mu \mathrm{l}$ suspension of streptomycin-sensitive C. michiganensis strain BT-0505 at $10^{8} \mathrm{CFU} / \mathrm{ml}$ was spread on TBY-S300 plates. Streptomycin-resistant isolates were able to form colonies on the TBY-S300 plates at $28^{\circ} \mathrm{C}$ after 3 days.

Minimum inhibitory concentration determination. The minimum inhibitory concentration (MIC) of streptomycin for C. michiganensis was determined using a microdilution method with a 96 -well microtiter plate ( 8 rows $\times 12$ columns). Each well contained $135 \mu \mathrm{l}$ of TBY broth and $15 \mu \mathrm{l}$ of $C$. michiganensis $\left(10^{6}\right.$ $\mathrm{CFU} / \mathrm{ml}$ ). The final concentrations in each column (from column 2 to column 12) were $0,1,2,4,8,16,32,64,128,256$, and $512 \mu \mathrm{g} / \mathrm{ml}$ streptomycin. Column 1 served as a blank control. In another trial, the concentrations from column 2 to column 12 were $0,100,200,300$, $400,500,1,000,2,000,3,000,4,000$, and 5,000 $\mu \mathrm{g} / \mathrm{ml}$ streptomycin. Four replicates of each strain were shaken $(120 \mathrm{rpm})$ for $24 \mathrm{~h}$ at $28^{\circ} \mathrm{C}$ before measuring the optical density with a Tecan infinite F200 microplate reader at $600 \mathrm{~nm}$.

DNA extraction, RNA extraction, and quantitative PCR. DNA from $C$. michiganensis strains was extracted using the

A
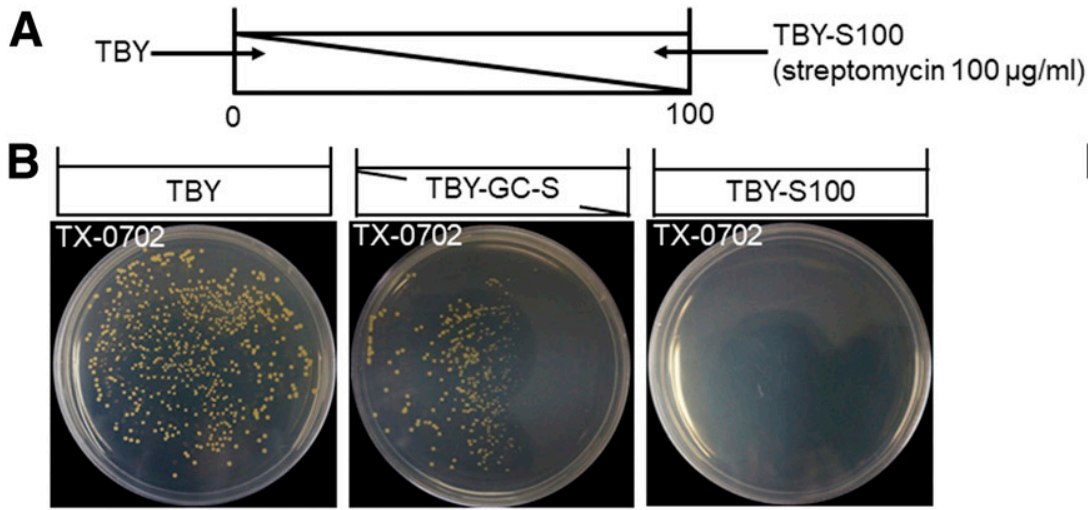

C
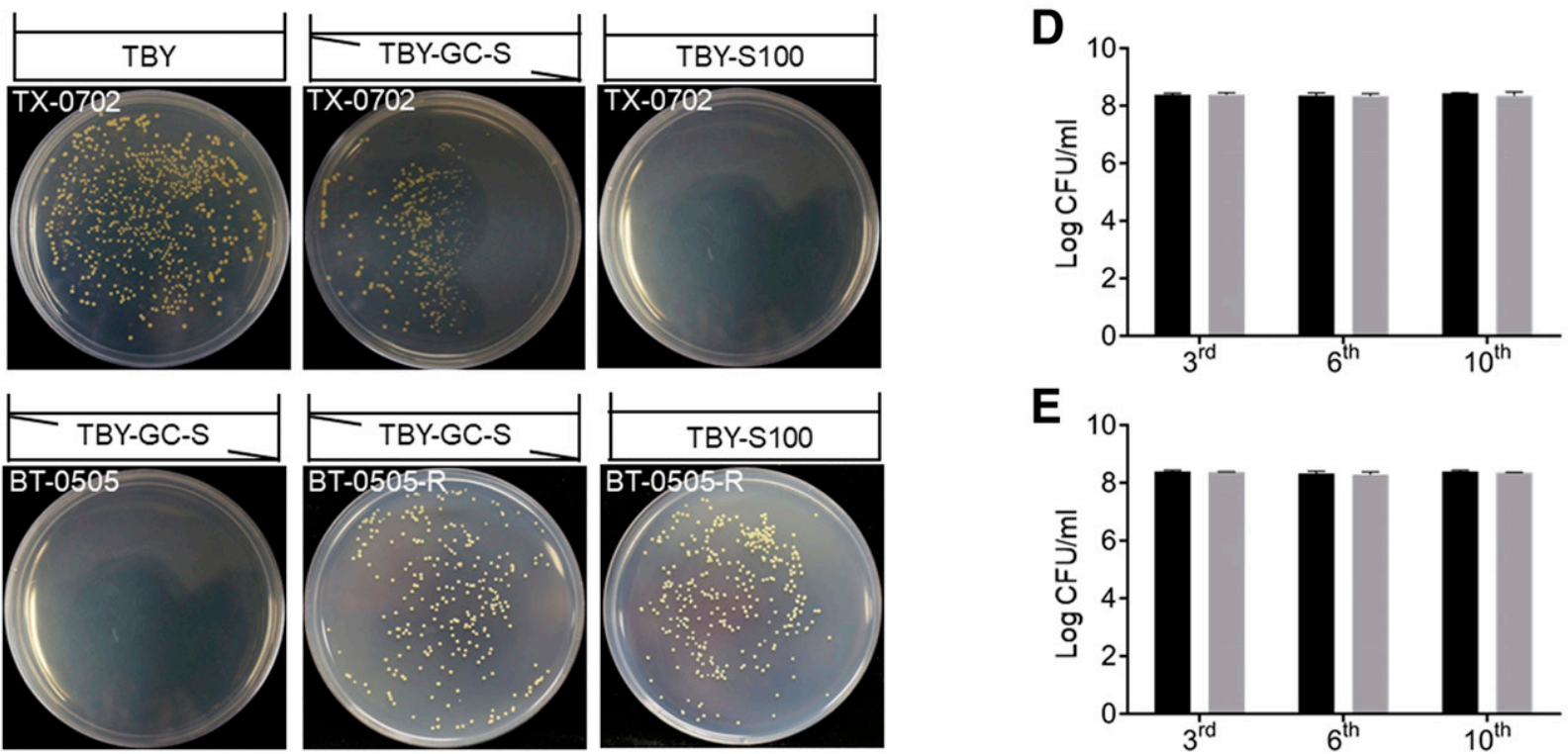

TBY

TBY-S50

\section{E}

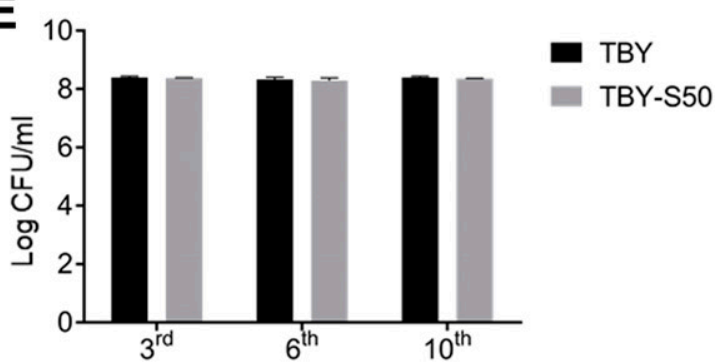

Fig. 1. Identification and induction of streptomycin resistance in Clavibacter michiganensis strains. A, Diagram of streptomycin gradient plates (tryptone broth with yeast-gradient concentration-streptomycin [TBY-GC-S]). B, The 179 C. michiganensis isolates collected worldwide were analyzed for streptomycin resistance. The Chinese strain, TX-0702, exhibited spontaneous resistance to streptomycin. Bacterial morphology on different media is shown after 3 days. C, An induced resistant strain (BT-0505-R) was obtained after plating sensitive parental strain BT-0505 on tryptone broth with yeast (TBY) plates containing $300 \mu \mathrm{g} / \mathrm{ml}$ streptomycin, and it can grow on TBY-GC-S and tryptone broth with yeast medium with $100 \mu \mathrm{g} / \mathrm{ml}$ streptomycin added (TBY-S100) media. D, The resistance of TX-0702 is stable after subculturing 10 times. E, The resistance of BT-0505-R is stable after subculturing 10 times. D and E, No significant differences were detected after analysis of variance $(P<0.05, n=3$; error bars indicate standard deviation). TBY-S50, tryptone broth with yeast plates with $50 \mu \mathrm{g} / \mathrm{ml}$ streptomycin. 
ChargeSwitch gDNA Mini Bacteria Kit (Invitrogen). Total RNA was extracted using the SV Total RNA Isolation System (Promega) with $8 \pm 0.6 \times 10^{8} \mathrm{CFU} / \mathrm{ml}$ bacteria (equivalent to optical density $[\mathrm{OD}]_{600}$ value of $1.0 \pm 0.03$ ). The DNA and RNA concentrations were estimated by NanoDrop 2000 (Thermal). In a $20-\mu$ reaction volume, $6 \mu$ of RNA was used to synthesize complementary DNA by using the PrimeScript RT reagent Kit with genomic DNA eraser (Takara). Real-time quantitative PCR (qPCR) was performed with the SYBR Premix DimerEraser Kit (Takara) in a 20- $\mu$ l reaction volume using the ABI 7500fast (Applied Biosystem) system following a three-step protocol. The software PrimerPremier 5 was used to design $C$. michiganensis-specific primers for genes putatively involved in antibiotic resistance. All primer sequences are listed in Supplementary Table S2, and PCR parameters are listed in Supplementary Table S3.

Comparative genome analyses. The total DNA of $C$. michiganensis strains BT-0505, TX-0702, and BT-0505-R were extracted using the ChargeSwitch gDNA Mini Bacteria Kit (Invitrogen). Whole-genome sequencing was performed with the Illumina HighSeq2000 platform. The genome data were de novo assembled with the SPAdes (Bankevich et al. 2012). Draft genomes were annotated by Prokka (Seemann 2014), and variations were visualized by Circos (Krzywinski et al. 2009). For resistance gene mining, genomes of NCPPB382, BT-0505, TX-0702, and BT-0505$\mathrm{R}$ were analyzed in the CARD (Jia et al. 2017).

Recombinant DNA manipulation. Putative streptomycin resistance-related genes were amplified from TX-0702 genomic DNA. To generate a knockout cassette, the upstream 1,000 bp and downstream 1,000 bp of candidate genes was amplified. The selective marker cmx cassette encoding chloramphenicol resistance was acquired from pOKU9 $\mathrm{cmB} \alpha$ (Kaup et al. 2005). All three fragments were amplified and cloned into pUC19 using InFusion technology (Clontech). The resulting suicide plasmid was transformed into Escherichia coli GM48, miniprepped, and used to electroporate to $C$. michiganensis strain TX-0702. The electroporation was carried out as previously described; $1 \mu \mathrm{g}$ of denatured plasmid was transformed into $100 \mu \mathrm{l}$ of TX-0702 competent cells under the following parameters: $12.5 \mathrm{kV} / \mathrm{cm}$ voltage, $25 \mu \mathrm{F}, 600 \Omega$, and time constant of 12 to $16 \mathrm{~ms}$ (Kirchner et al. 2001). The cells were incubated at $28^{\circ} \mathrm{C}$ for $3 \mathrm{~h}$ after adding $400 \mu \mathrm{l}$ of sorbitol broth (SB); then, they were spread on SB agar plates with $10 \mu \mathrm{g} / \mathrm{ml}$ chloramphenicol and incubated at $28^{\circ} \mathrm{C}$ for 5 to 7 days. Transformants were confirmed by PCR and DNA sequencing.

The transposon vector pKGT452C $\beta$ was used to construct a mutant exhibiting loss of streptomycin resistance in strain TX-0702 by random chromosomal insertion (Kirchner et al. 2001). The insertion site was identified by thermal asymmetric interlaced (TAIL)-PCR (Liu and Chen 2007). The primers for TAIL-PCR were designed based on the chloramphenicol resistance cassette and the right inverted repeat sequence on plasmid pKGT452C $\beta$.

For gene complementation, the intact rps $L$ gene from BT-0505 and BT-0505-R was amplified. HindIII and EcoRV restriction enzyme sites were added on the forward and reverse primer, respectively. The Clavibacter-E. coli shuttle plasmid pHN216 was cleaved with HindIII and EcoRV enzymes and then, ligated with the $r p s L$ fragment (Laine et al. 1996). The recombinant plasmids were transformed into E. coli GM48 cells and subsequently transformed into BT-0505 and BT-0505-R competent cells. Neomycin (50 $\mu \mathrm{g} / \mathrm{ml}$ ) resistance on $\mathrm{pHN} 216$ was used as the selectable marker. The transformants were confirmed by PCR, and their MICs for streptomycin were determined. Streptomycin-resistant candidate genes from TX-0702 were manipulated as described above and transformed into BT-0505 to determine their roles in mediating resistance.

C. michiganensis inoculation assays. Pathogenicity tests on tomato were performed by prick inoculation. Four-week-old tomato plants (Solanum lycopersicum cv. Moneymaker) were pricked with a sterilized needle on the stem between the two cotyledons, and a $10-\mu 1$ suspension of $C$. michiganensis was pipetted into the wound site. The strains used for inoculation include the streptomycinsensitive strain BT-0505, the spontaneous streptomycin-resistant strain TX-0702, and three single knockout mutants generated from the parental strain TX-0702 (TX-0702 $\Delta 02040$, TX-0702 $\Delta 03055$, and TX-0702 $\Delta 03056$ ) as well as the induced streptomycin-resistant strain BT-0505-R. The concentration of the suspension was adjusted to $3 \times 10^{8} \mathrm{CFU} / \mathrm{ml}\left(\mathrm{OD}_{600}=0.4\right)$ and washed twice with sterilized $0.85 \% \mathrm{NaCl}$ solution before use. Each experiment included six plants per treatment. Mock inoculation with $0.85 \%$ $\mathrm{NaCl}$ was used as a negative control. The symptoms were photographed at 7 days postinoculation (dpi) to observe the canker area on the tomato stem, and the lesion size was calculated with Fiji software (Schindelin et al. 2012). To calculate canker lesion sizes after inoculation, we photographed individual stems next to a ruler. Next, the area of each lesion was calculated in Fiji software by selecting the region with canker and calculating the area using the ruler as a guide. At $7 \mathrm{dpi}$, a $1-\mathrm{cm}$ stem segment $1 \mathrm{~cm}$ above the inoculated site from all six plants was harvested and weighed (the weight of the $1-\mathrm{cm}$ stem segment is $\sim 0.5 \mathrm{~g}$ ). Then, it was surface disinfected with $1 \% \mathrm{NaOCl}$ solution for $1 \mathrm{~min}$ and washed twice with sterilized water. The stem segment was frozen in liquid nitrogen and homogenized by the Retsch MM400 ball-milling machine at $30 \mathrm{~Hz}$ for $2 \mathrm{~min}$. The powder of each sample was resuspended and diluted 10 -fold in a $0.85 \% \mathrm{NaCl}$ solution. Samples were dilution plated onto modified Corynebacterium nebraskensisselective (mCNS) media (semiselective medium for C. michiganensis) (Gitaitis et al. 1991) and incubated at $28^{\circ} \mathrm{C}$ for 5 days. Then, the colonies on mCNS media were counted to calculate CFU per gram of tissue. The difference of concentration of reisolated strains was analyzed by one-way analysis of variance (ANOVA) followed with the Tukey multiple comparison test in Graphpad Prism 7 software.

To determine the ability of streptomycin to inhibit bacterial growth and blister symptom development, suspensions of $C$. michiganensis BT-0505, TX-0702, and BT-0505-R were prepared as described above and then, sprayed on leaves of 4 -week-old tomato plants. The spray inoculation method was used instead of prick inoculation because of rapid systemic infection and death of tomato plants caused by wound inoculation. Therefore, this less invasive method was chosen to better compare treatment efficacy. Blister observation and disease assessment standard were described in the work of Chalupowicz et al. (2017). Streptomycin was dissolved in water at concentrations of $0,50,100$, and $200 \mu \mathrm{g} / \mathrm{ml}$ and sprayed 3 days after C. michiganensis inoculation. Six inoculated plants were used for each treatment. Bacterial isolation from leaves was performed at 21 dpi with inoculated leaf samples; $0.1 \mathrm{~g}$ of leaves were surface disinfested, ground in liquid nitrogen with a mortar and pestle, and processed as described above for prick inoculation. Bacterial titers were calculated by dilution plating. We compared the difference in bacterial titers under different concentration of streptomycin treatment for each strain individually. Significant differences were determined by one-way ANOVA followed by the Tukey multiple comparison test for each bacterial strain $(\alpha=0.05)$ with Graphpad Prism 7 software. ANOVA terms included streptomycin rate and error. Both pathogenicity tests and the streptomycin trials were repeated three times.

\section{RESULTS}

Evaluation of streptomycin resistance in $C$. michiganensis strains. To evaluate the frequency of streptomycin resistance in C. michiganensis, 179 strains isolated from the diseased tomato samples worldwide were analyzed (Fig. 2A). The $179 C$. michiganensis strains were incubated on plates exhibiting GCs of streptomycin from 0 to $100 \mu \mathrm{g} / \mathrm{ml}$ within a single petri dish (TBYGC-S) (Fig. 1A). Three strains (TX-0702, TX-0703, and TX-0704) isolated in 2007 from Hebei Province in China exhibited spontaneous resistance to streptomycin, whereas the remaining 176 strains 
could not grow on TBY-GC-S medium or TBY-S20 medium, and no significant difference was detected based on ANOVA $(P<0.05, n=$ 3; error bars indicate standard deviation) (Fig. 2B). These resistant C. michiganensis strains can grow well on TBY-GC-S medium. However, as the concentration of streptomycin increased on TBYGC-S medium (from 0 to $100 \mu \mathrm{g} / \mathrm{ml}$ ), the colonies became smaller, and no colonies were detected at higher streptomycin concentrations (around $100 \mu \mathrm{g} / \mathrm{ml}$ ). Furthermore, these three strains cannot grow on TBY-S100 medium (Fig. 1B). These data demonstrated that strains exhibiting moderate streptomycin resistance were naturally present in China.

Multilocus sequence analysis was performed to explore the genetic relationship of strains exhibiting streptomycin resistance (TX-0702) and sensitivity (BT-0505) with previously reported Clavibacter species. Six housekeeping genes ( $a t p D$, dnaK, gyrB, $p p K$, recA, and $r p o B$ ) were used to generate a maximum likelihood phylogeny tree. The result indicated that strains BT-0505 and TX-0702 cluster with pathogenic $C$. michiganensis on tomato, and TX-0702 was present in the same clade as the reference strain NCPPB382 (Fig. 2C).

We also sought to determine if streptomycin resistance could be obtained by experimental evolution. For these experiments, we used the sensitive strain BT-0505 isolated in 2005 from the Inner Mongolia autonomous region and strain GS-12104 isolated from Gansu Province in 2012. Streptomycin resistance was induced by culturing the sensitive strains BT-0505 and GS-12104 on TBY-S300 medium at $28^{\circ} \mathrm{C}$. Several colonies were able to grow on plates containing streptomycin after 3 days. Next, we investigated single induced resistant colonies named BT-0505-R and GS-12104-R that could consistently form colonies on both TBY-GC-S and TBY-S100 media (Fig. 1C). The stability of both spontaneous and induced resistance was tested by incubating the 3rd, 6th, and 10th subcultures of bacteria of TX-0702 and BT-0505-R on TBY and TBY-S50 media followed by incubation for 3 days at $28^{\circ} \mathrm{C}$. The titer of each strain on the two media had no significant difference when analyzed by ANOVA $(P<0.05, n=3$; error bars indicate standard deviation), which indicates that both spontaneous resistance and induced resistance are stable in 10 subcultures (Fig. 1D and E).

Comparative genetic analyses. To gain insight into genetic mechanisms responsible for streptomycin resistance, sensitive C. michiganensis strain BT-0505, spontaneous resistant strain TX-0702, and induced resistant strain BT-0505-R were sequenced on the Illumina HiSeq2000 platform. The genome assembly information is listed in Table 1. Genome sizes and GC content are similar to the reference strain NCPPB382. The genome of the spontaneous resistant strain TX-0702 is $3.4 \mathrm{Mb}$, and the sensitive strain BT-0505 is $3.3 \mathrm{Mb}$. Moreover, TX-0702 has two plasmids (pCM1 and pCM2), whereas BT-0505 and BT-0505-R only possesses the $\mathrm{pCM} 1$ plasmid. Whole-genome comparative analyses of BT-0505, TX-0702, and NCPP382 revealed significant collinearity (Fig. 3A, B, and C).

To identify potential loci responsible for streptomycin resistance, the three assembled $C$. michiganensis genomes and the reference genome NCPPB382 were analyzed in the CARD. The results
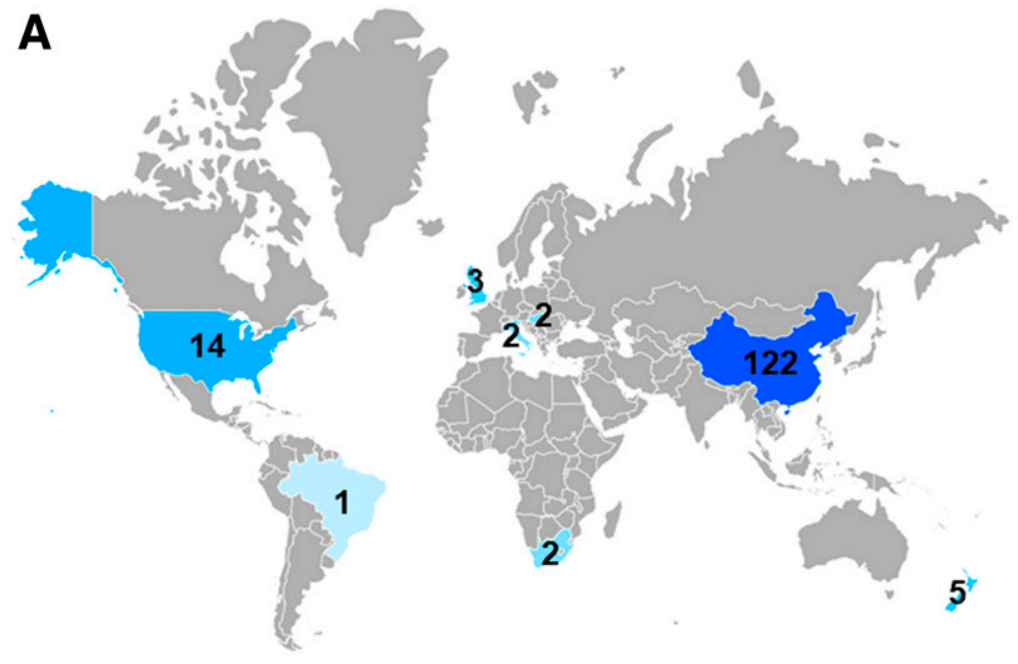

B
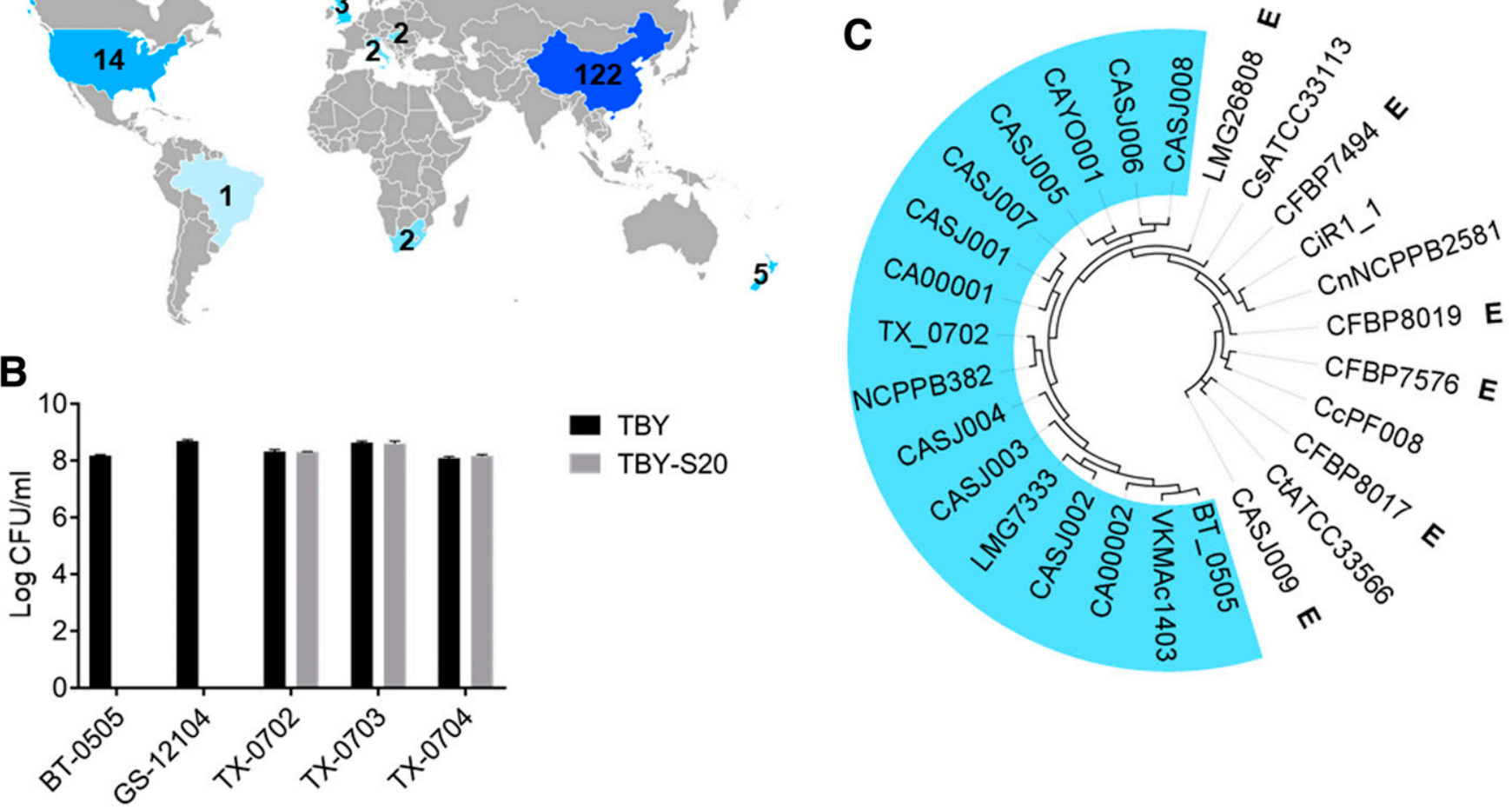

Fig. 2. Clavibacter michiganensis strains used in this study. A, Geographical distribution of tested strains (28 strains with unknown origins are not depicted). B, Growth of sensitive and resistant strains on tryptone broth with yeast (TBY) and tryptone broth with yeast plates with $20 \mu \mathrm{g} / \mathrm{ml}$ streptomycin (TBY-S20) media. BT-0505 and GS-12104 are representative of the 176 sensitive strains. The titers of strains TX-0702, TX-0703, and TX-0704 did not show significant differences between TBY and TBY-S20 media. No significant differences were detected based on analysis of variance $(P<0.05, n=3$; error bars indicate standard deviation). C, Phylogeny $C$. michiganensis subspecies based on six housekeeping genes ( $a t p D, d n a K, \operatorname{gyr} B, p p K, r e c A$, and $r p o B)$. A maximum likelihood approach was used to obtain the phylogenetic tree using MEGA software version 6 with 1,000 bootstrap replicates. Pathogenic $C$. michiganensis strains are labeled in light blue. Cc, Clavibacter capsici; Ci, Clavibacter insidiosus; Cn, Clavibacter nebraskensis; Cs, Clavibacter sepedonicus; and Ct, Clavibacter tessellarius. 
identified 14 genes related to aminoglycoside antibiotic resistance in strains BT-0505 and TX-0702, whereas NCPPB382 has 15 genes. However, most of the genes show low amino acid identity with the reported genes in the $\mathrm{CARD}(<40 \%)$, and none of them are related to streptomycin resistance.

A mutation in rps $L$ mediates resistance to streptomycin in B T-0505-R. We identified a single gene, rps $L$, with high amino acid identity (85\%) to previous loci controlling streptomycin resistance in strains BT-0505-R and GS-12104-R (Supplementary Table S4). The rpsL gene encodes the ribosome S12 protein, the target of streptomycin (Chiou and Jones 1995). In strain BT-0505-R, seven single-nucleotide polymorphisms (SNPs) were found compared with parental sensitive strain BT-0505. One of the SNPs is a mutation of the $r p s L$ gene, resulting in a point mutation at the 128th nucleotide and leading to a change from lysine to arginine (Fig. 3D). SNPs were confirmed by PCR amplification and Sanger sequencing. Because the $r p s L$ knockout is lethal, the intact $r p s L$ gene from both BT-0505 $(r p s L-S)$ and BT-0505-R (rpsL-R) was amplified and used for complementation assays. The function of the SNP within $r p s L$ was verified by transforming the $r p s L-R$ (resistance) allele into sensitive strain BT-0505 and the $r p s L-S$ (sensitive) allele into resistant strain BT-0505-R. The MIC increased from 4 to $64 \mu \mathrm{g} / \mathrm{ml}$ in strain BT-0505 after transformation with rps $L-R$, whereas in strain BT-0505-R, the MIC decreased from 5,000 to 2,000 $\mu \mathrm{g} / \mathrm{ml}$ after acquisition of $r p s L-S$. This result indicates that the mutation in rps $L$ is responsible for the streptomycin resistance in strain BT-0505-R (Fig. 3F).

Additionally, we obtained another induced resistance strain named BT-0505-R-2 that also harbors a point mutation in the rpsL gene but at the 262th nucleotide, causing a change from lysine to glutamic acid. However, this mutation also impaired the growth of C. michiganensis. BT-0505-R-2 required 7 days at $28^{\circ} \mathrm{C}$ for colony formation on TBY plates, and its growth was also retarded compared with BT-0505-R in TBY broth (Supplementary Fig. S1).

Identification of streptomycin-sensitive transposon insertions in TX-0702. In addition to our experimental evolution of BT-0505, we also sought to identify the source of naturally occurring streptomycin resistance in a $C$. michiganensis field strain. For this purpose, we focused on the streptomycin-resistant strain TX-0702. TX0702 has a streptomycin MIC of $128 \mu \mathrm{g} / \mathrm{ml}$. To identify potential streptomycin resistance-related loci in the strain TX-0702, we generated a mutant library using the transposon vector pKGT452C $\beta$ and screened for insertion mutants losing streptomycin resistance. The transposon insertion confers resistance to chloramphenicol. Transforming the vector into strain TX-0702 generated a library consisting of random insertion mutants that exhibit chloramphenicol resistance. After screening $\sim 12,000$ transformants, we obtained 53 mutants that can grow on TBY containing $10 \mu \mathrm{g} / \mathrm{ml}$ chloramphenicol but cannot grow on TBY with $10 \mu \mathrm{g} / \mathrm{ml}$ chloramphenicol and $50 \mu \mathrm{g} / \mathrm{ml}$ streptomycin. We determined the MIC of each mutant and identified 31 mutants with streptomycin MICs of $<20 \mu \mathrm{g} / \mathrm{ml}$ for additional characterization.

To identify the location of transposon insertions, DNA from the 31 candidate mutants was extracted and used as templates for TAILPCR. After three rounds of PCR and agarose gel electrophoresis, PCR products were gel purified, cloned into the $\mathrm{T}$ vector, and sent for Sanger sequencing (Fig. 4A).
Three separate insertion sites were identified from the 31 mutants (Fig. 4A and B). Two transposon insertions were located on plasmid pCM2. We analyzed the sequence of pCM2 of strain TX-0702, but there are no antibiotic resistance-related genes based on CARD searching. The final transposon insertion was located between the chromosomal genes 03055 and 03056 . Both of these genes encode proteins of unknown function.

Using a combination of CARD analyses and TAIL-PCR results, we selected 15 candidate genes potentially related to streptomycin resistance in TX-0702 for genetic analyses (Table 2). These candidate genes include six putative antibiotic resistance-related genes (including a streptomycin phosphotransferase) and seven ABC transporters and efflux pumps as well as two hypothetical proteins. To investigate the importance of candidate genes, 15 suicide plasmids containing knockout cassettes were constructed and transformed into wild-type $C$. michiganensis TX-0702. For each gene, about 500 transformants were screened on TBY with $10 \mu \mathrm{g} / \mathrm{ml}$ chloramphenicol and TBY with $10 \mu \mathrm{g} / \mathrm{ml}$ chloramphenicol and $20 \mu \mathrm{g} / \mathrm{ml}$ streptomycin. The colonies that grew on TBY with $10 \mu \mathrm{g} / \mathrm{ml}$ chloramphenicol were selected, and knockouts were confirmed by PCR with specific primers and sequencing. Knockout mutants of single genes in TX-0702 for 02040 (putative ABC transporter), 03055 (hypothetical protein), and 03056 (hypothetical protein) were sensitive to streptomycin, with MICs of $<20 \mu \mathrm{g} / \mathrm{ml}$ (Table 3). The TX-0702 02040 knockout exhibited slower growth on TBY plates with chloramphenicol, whereas the 03055 and 03056 mutants were comparable with the TX-0702 growth rate. Therefore, knockouts of diverse streptomycin candidate genes in TX-0702 resulted in increased sensitivity to streptomycin.

Genes 03055 and 03056 are both annotated as hypothetical proteins, and they were identified from the TX-0702 transposon mutant library described above. We also attempted to complement both genes using native promoters and a putative chloramphenicol promoter amplified from plasmid $\mathrm{pOKU} 9 \mathrm{CmB} \alpha$, but we were unable to restore streptomycin resistance (Table 3). Resistance to streptomycin was not restored by complementation of either 03055 or 03056 in the corresponding TX-0702 mutants, although the expressions of these two genes were confirmed by qPCR in complementation strains (Fig. 4C and D). Taken together, these results indicate that the streptomycin resistance present in TX-0702 is a novel type of resistance and remains elusive.

To determine if the transposon insertion between 03355 and 03056 induced SNPs or affected the expression of other genes related to streptomycin resistance, we analyzed the sequence and expression of rpsL and other reported genes related to the streptomycin resistance, including gidB, rrs (16S ribosomal DNA sequence), and $\operatorname{str} B$, in both sensitive and resistant $C$. michiganensis strains. However, no mutation related to resistance was found in these genes for TX-0702 or other strains exhibiting spontaneous streptomycin resistance. We also tested the relative expression of $r p s L$, gidB, rrs, and groEL genes in strains BT-0505, TX-0702, and BT-0505-R. The expression of $r p s L$ in TX-0702 was highly upregulated after growth in $50 \mu \mathrm{g} / \mathrm{ml}$ streptomycin in the TBY broth, whereas the expressions of the other three genes were not

TABLE 1 . Genome assembly of sequenced Clavibacter michiganensis strains

\begin{tabular}{|c|c|c|c|c|c|c|c|c|c|}
\hline \multirow[b]{2}{*}{ Strain } & \multirow[b]{2}{*}{ Contigs } & \multirow[b]{2}{*}{ Size (bp) } & \multirow[b]{2}{*}{$\mathrm{GC}(\%)$} & \multirow[b]{2}{*}{ CDS } & \multirow[b]{2}{*}{ Plasmids } & \multicolumn{4}{|c|}{ Reads mapping to reference genomes } \\
\hline & & & & & & $\mathrm{NCPPB} 382(\mathrm{Cm})^{\mathrm{a}}$ & $\mathrm{PF} 008(C c)^{\mathrm{b}}$ & LMG26808 $(\mathrm{Cm})$ & $\mathrm{CF} 11(\mathrm{Cm})$ \\
\hline NCPPB382 & 1 & $3,297,891$ & 72.53 & 3,114 & $\mathrm{pCM} 1 / \mathrm{pCM} 2$ & $\mathrm{ND}^{\mathrm{c}}$ & ND & ND & ND \\
\hline BT-0505 & 14 & $3,294,995$ & 72.54 & 3,055 & pCM1 & $94.90 \%(428.2 \times)^{\mathrm{d}}$ & $82.67 \%(105.2 \times)$ & $85.19 \%(247.5 \times)$ & $85.53 \%(104.5 \times)$ \\
\hline BT-0505-R & 12 & $3,295,105$ & 72.59 & 3,055 & pCM1 & $94.94 \%(399.5 \times)$ & $81.36 \%(96.7 \times)$ & $84.92 \%(227.5 \times)$ & $84.18 \%(94.9 \times)$ \\
\hline TX-0702 & 16 & $3,416,498$ & 72.30 & 3,189 & $\mathrm{pCM} 1 / \mathrm{pCM} 2$ & $95.72 \%(181.2 \times)$ & $77.15 \%(38.5 \times)$ & $84.71 \%(85.6 \times)$ & $79.12 \%(35.5 \times)$ \\
\hline
\end{tabular}

a $C$. michiganensis, nonpathogenic.

b Clavibacter capsici.

c ND, none detected.

d Depth of mapping. 
(Supplementary Fig. S2). We analyzed the sequence upstream of rpsL in strains BT-0505, TX-0702, and BT-0505-R and found no difference. Transformation with rpsL-S (sensitive; from BT-0505) into strain BT-0505 did not change its susceptibility to streptomycin, and therefore, we inferred that the overexpression of $r p s L$ is not responsible for the resistance in strain TX-0702.

Pathogenicity test and the streptomycin effectiveness. To test whether loss of streptomycin resistance in TX-0702 alters
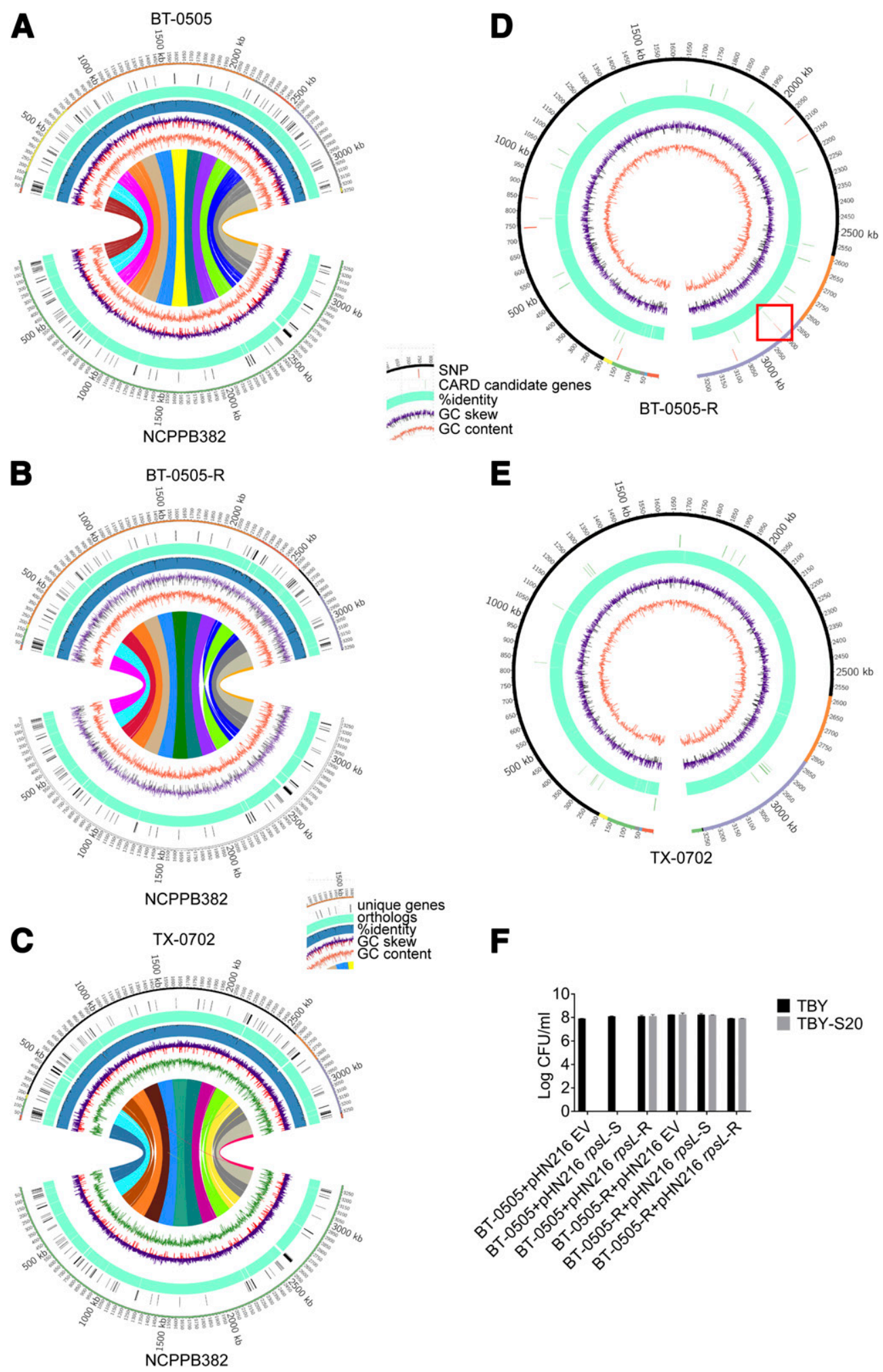

$\mathbf{F}$
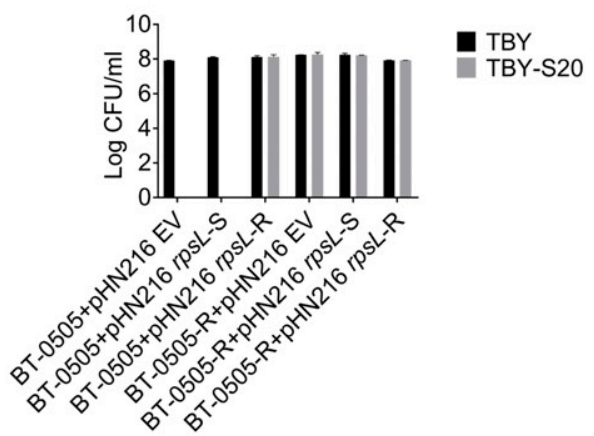

Fig. 3. Circos plots comparing genomes of BT-0505, TX-0702, and NCPPB382. A, B, and C, Circos plots visualize genome-wide comparisons of strains BT-0505, TX-0702, and BT-0505-R with the NCPP382 reference strain, respectively. Chromosomes are depicted in arbitrary shades (outer ring). D, The schematic of the chromosome of strain BT-0505-R. The seven single-nucleotide polymorphisms (SNPs) not found in the parental strain BT-0505 are labeled in red, and 20 candidate antibiotic resistance genes identified in the comprehensive antibiotic resistance database (CARD) are labeled in green. The red box indicates the point mutation of the rpsL gene. E, The schematic of the chromosome of strain TX-0702. F, The titer of different strains on tryptone broth with yeast (TBY) and tryptone broth with yeast medium containing $20 \mu \mathrm{g} / \mathrm{ml}$ streptomycin (TBY-S20) plates after complementation using the Clavibacter-Escherichia coli shuttle vector pHN216 containing rpsL-S or rpsL-R alleles in strains BT-0505 or BT-0505-R, respectively. Empty pHN216 was transformed into BT-0505 and BT-0505-R as control. Error bars indicate standard deviation. 
pathogenicity on tomato, we performed disease assays on tomato. Four-week-old tomato plants (S. lycopersicum 'Moneymaker') were inoculated. After 7 days, the canker area on stems was photographed for disease evaluation. The results showed that the canker lesion sizes caused by the streptomycin-resistant TX-0702 and its resistance loss mutants were larger than lesions on plants inoculated with the streptomycin-sensitive strain BT-0505 and the induced streptomycin-resistant strain BT-0505-R (Supplementary
Fig. S3). The TX-0702 knockouts in 02040, 03055, and 03056 did not impair pathogenicity compared with wild-type TX-0702 (Fig. $5 \mathrm{~A})$. Bacterial titers were also analyzed, and titers between strains were not statistically different (Fig. 5B).

The ability of exogenous streptomycin application to control disease caused by $C$. michiganensis streptomycin-sensitive strain BT-0505 and the streptomycin-resistant strains TX-0702 and BT0505-R in tomato was also examined. C. michiganensis suspensions

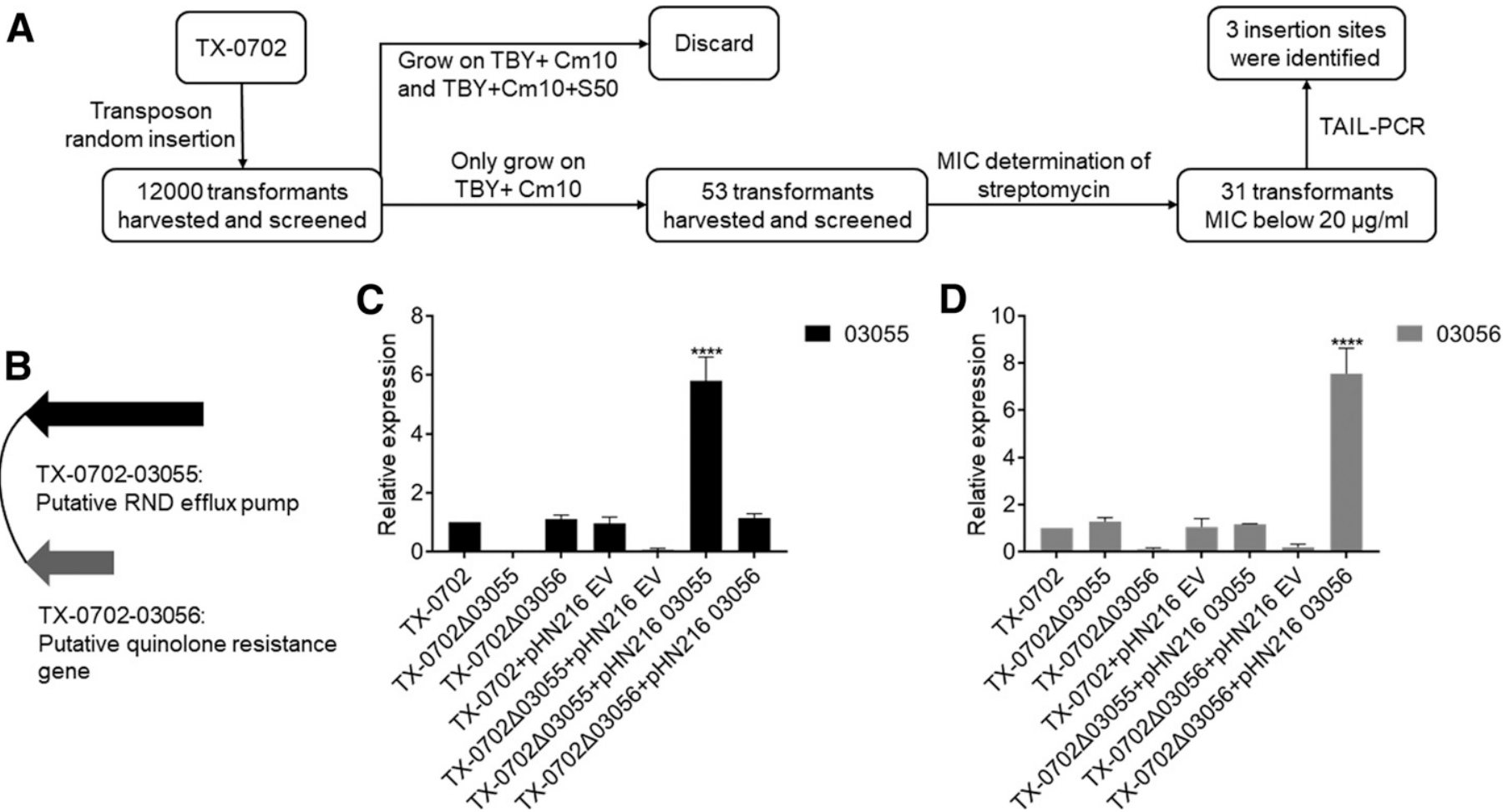

Fig. 4. The analyses of potential resistance-related genes in strain TX-0702. A, The workflow to identify loss of streptomycin resistance using transposon-based insertion. B, Diagram and putative function of TX-0702-03055 and TX-0702-03056. The labeled functions of two genes were identified in the comprehensive antibiotic resistance database, but they are based on low amino acid similarity. C and D, The relative expression of candidate streptomycin resistance genes TX-0702-03055 and TX-0702-03056 in different strains, respectively. Wild-type TX-0702 was used as a control. Expression after complementation with the plasmid pHN216 containing the indicated loci. Gene expression was normalized to the geometric mean of reference genes bipA, gapA, and gyrB. Significant differences were detected by analysis of variance followed by the Tukey multiple comparisons test $(P<0.05, n=3$; error bars indicate standard deviation). MIC, minimum inhibitory concentration; RND, resistance-nodulation-cell division; TAIL, thermal asymmetric interlaced; TBY, tryptone broth with yeast. The asterisks indicate significant difference.

TABLE 2. Candidate resistance-related genes in strain TX-0702

\begin{tabular}{llr}
\hline Source & \multicolumn{1}{c}{ Function } & \multicolumn{1}{c}{ Gene identification } \\
\hline Genome annotation & Putative streptomycin phosphotransferase & 01000,01001 \\
Genome annotation & Predicted resistant gene & $01202,01998,02040,02893$ \\
Comparative analyses & ABC transporter gene & $01023,01344,02026,02096$ \\
Comparative analyses & RND multidrug efflux pump & $00808,02011,03021$ \\
Transposon insertion site & Hypothetical protein & 03055,03056 \\
\hline
\end{tabular}

a Resistance-nodulation-cell division.

TABLE 3. Minimum inhibition concentration (MIC) of different mutant and complementation Clavibacter michiganensis strains on streptomycin

\begin{tabular}{|c|c|c|c|}
\hline Strain & $\operatorname{MIC}(\mu \mathrm{g} / \mathrm{ml})$ & Strain & $\mathrm{MIC}(\mu \mathrm{g} / \mathrm{ml})$ \\
\hline BT-0505 & 4 & TX-0702 & 128 \\
\hline BT-0505 + pHN216 EV & 4 & TX-0702 $\Delta 02040$ & 16 \\
\hline BT-0505 + pHN216 rpsL- $S^{\mathrm{b}}$ & 4 & TX-0702 $\Delta 03055$ & 4 \\
\hline BT-0505-R & $>5,000$ & TX-0702 $\Delta 03055+$ pHN216 EV & 4 \\
\hline BT-0505-R + pHN216 EV & $>5,000$ & TX-0702 $\Delta 03056+$ pHN216 EV & 4 \\
\hline BT- $0505-\mathrm{R}+\mathrm{pHN} 216 r p s L-S$ & 2,000 & $\mathrm{TX}-0702 \Delta 03055+\mathrm{pHN} 21603055^{\mathrm{d}}$ & 4 \\
\hline BT-0505-R + pHN216 rpsL-R & $>5,000$ & $\mathrm{TX}-0702 \Delta 03056+\mathrm{pHN} 21603056^{\mathrm{d}}$ & 4 \\
\hline
\end{tabular}

a Plasmid pHN216, Clavibacter-Escherichia coli shuttle vector, used for gene complement. EV, empty vector.

b Intact sensitive rpsL gene amplified from strain BT-0505.

${ }^{\mathrm{c}}$ Intact resistant $\operatorname{rps} L$ gene with point mutation at the 128th nucleotide amplified from strain BT-0505-R.

${ }^{\mathrm{d}}$ Both native promoter and promoter of chloramphenicol resistance cassette ( $c m x$ cassette) amplified from pOKU9CmB $\alpha$ were tested. 
were sprayed on the leaves of 4-week-old tomato plants; then, four concentrations of streptomycin were applied after 3 days. Blister symptoms were observed on tomato leaves inoculated with all three C. michiganensis strains even when 50, 100, or $200 \mu \mathrm{g} / \mathrm{ml}$ streptomycin was applied. No blistering was observed in the water control at 7 and 14 dpi (Fig. 5C). We also observed a decreased titer of BT0505 with increasing streptomycin concentrations, whereas the titers of TX-0702 and BT-0505-R displayed no significant difference under every streptomycin concentration (TX-0702, $P=0.65$; BT0505-R, $P=0.52$ ) (Fig. 5D). Significant differences were detected for each bacterial genotype $(P<0.05, n=4$; error bars indicate standard deviation). Taken together, these data demonstrate that the streptomycin-resistant strains identified in the laboratory are unlikely to be controlled by streptomycin application on tomato.

\section{DISCUSSION}

Streptomycin is a common antibiotic used in disease management, including management of bacterial canker on tomato (Hausbeck et al. 2000; McManus et al. 2002). Prolonged application has led to streptomycin resistance in both $M$. tuberculosis (Crofton and Mitchison 1948; Gillespie 2002) and some Gram-negative phytopathgenic bacteria, including the genera Erwinia, Pseudomonas, and Xanthomonas (Han et al. 2004; Schroth 1979; Sundin and Bender 1994; Zhang et al. 2011). In this study, we identified three C. michiganensis strains resistant to streptomycin and provided insight into diverse genetic mechanisms controlling resistance.

Streptomycin targets the S12 protein of the ribosomal 30S subunit and interferes with protein synthesis (Chiou and Jones 1995). Mutations in rpsL, which encodes the S12 protein, can cause resistance to streptomycin (McManus et al. 2002). In the genera Erwinia and Xanthomonas, the mutations at 128th or 262th nucleotide in $r p s L$ resulted in streptomycin resistance (Chiou and Jones 1995; Zhang et al. 2011). In C. michiganensis strain BT-0505$\mathrm{R}$, a point mutation in rpsL at the 128th nucleotide resulting in a substitution of lysine to arginine caused resistance. Similar streptomycin-resistant $C$. michiganensis strains have been isolated in Chile, indicating that rpsL point mutants are one mechanism regulating streptomycin resistance in the genus Clavibacter (Valenzuela et al. 2019). We also generated strain BT-0505-R-2, which harbors a nonsynonymous SNP at the 262th nucleotide in rpsL gene, but the growth of this strain was impaired compared with the wild type. This is inconsistent with the results in Xanthomonas oryzae pv. oryzicola, in which the mutation at 262th nucleotide in
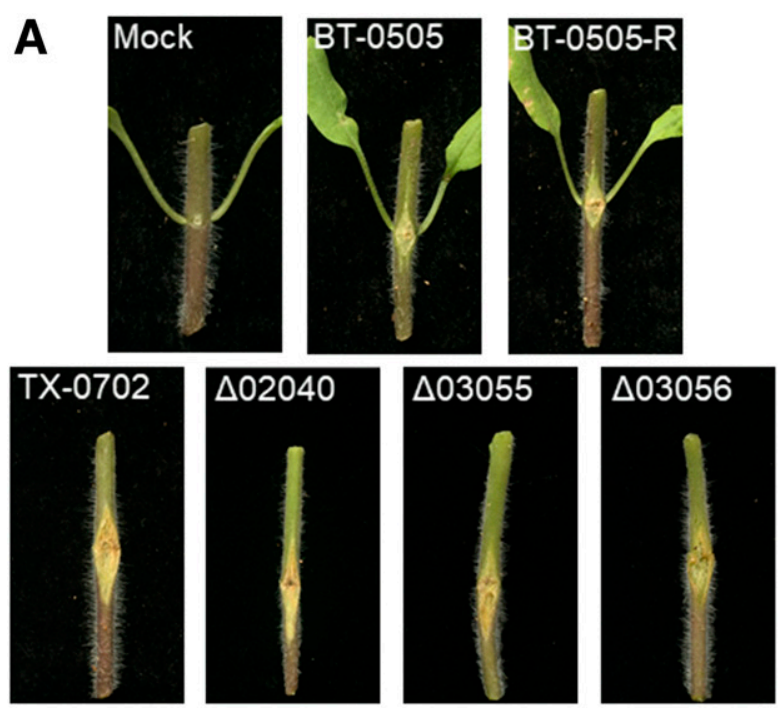

B

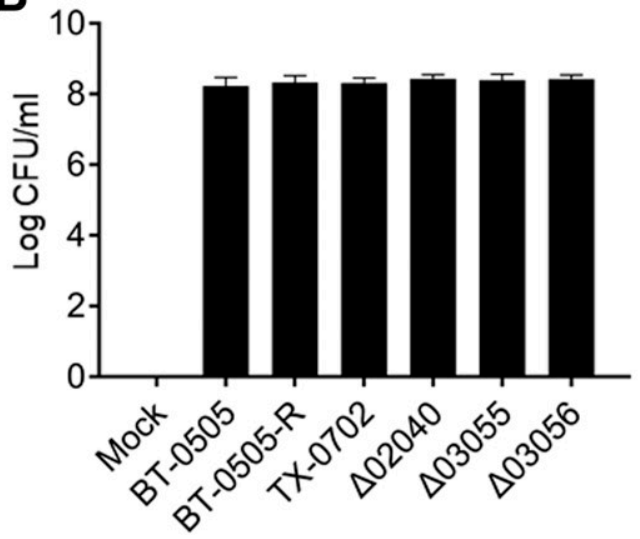

C
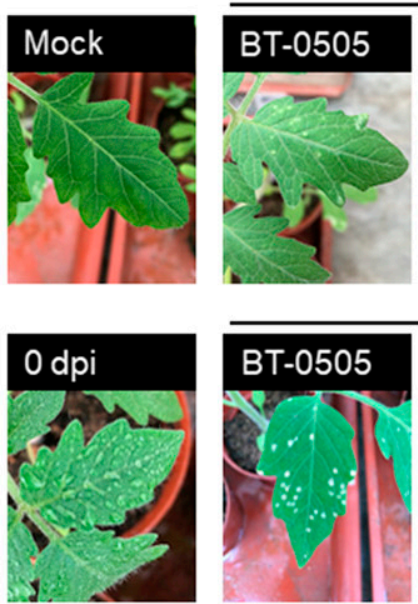

$7 \mathrm{dpi}$
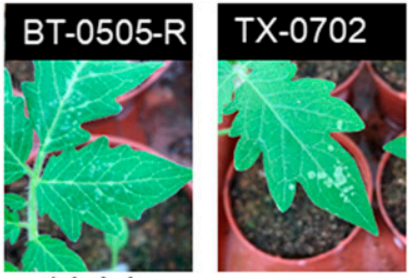

$14 \mathrm{dpi}$

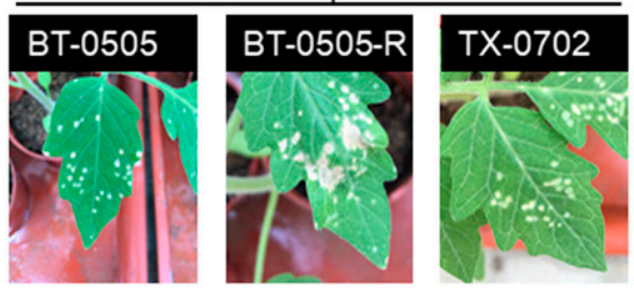

D

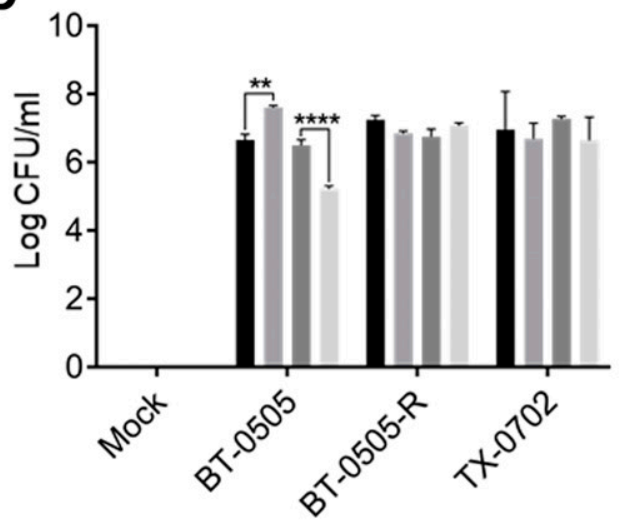

$0 \mathrm{ppm}$

$50 \mathrm{ppm}$

$100 \mathrm{ppm}$

$200 \mathrm{ppm}$

Streptomycin concentration $(\mu \mathrm{g} / \mathrm{ml})$

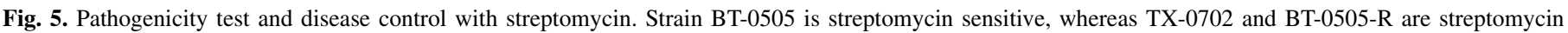

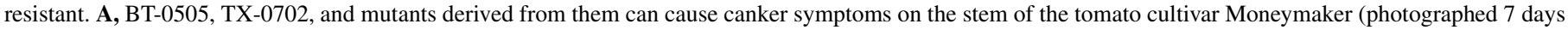

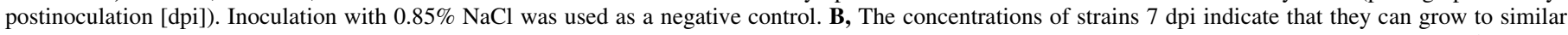

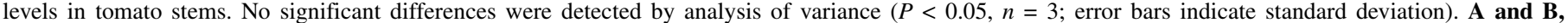

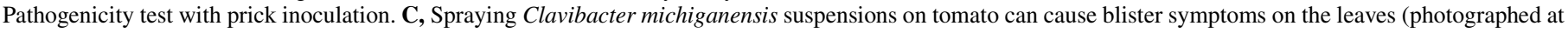

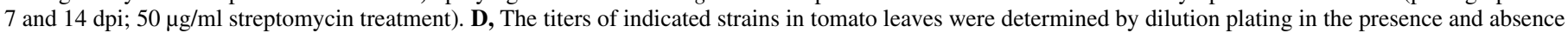

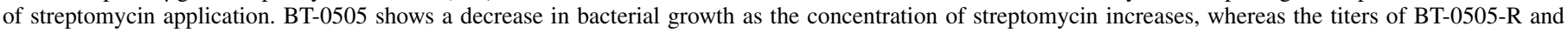

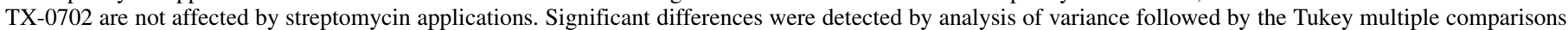

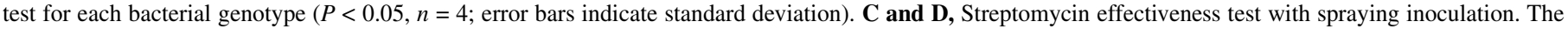
asterisks indicate significant difference. 
rpsL gene caused streptomycin resistance but did not affect the bacterial growth (Zhang et al. 2011). It is possible that additional SNPs in BT-05050-R-2 are responsible for its growth phenotype.

Moderate resistance to streptomycin is also related to streptomycininactivating enzymes and efflux pumps (McManus et al. 2002). For example, in Streptomyces griseus and Streptomyces glaucescens, the phosphotransferase $\operatorname{APH}(6)$ can inactivate streptomycin (Shaw et al. 1993). The $y k k C D$ efflux pump, which belongs to a small multidrug resistance family, has been reported to confer streptomycin and chloramphenicol resistance in Bacillus subtilis and E. coli, respectively (Jack et al. 2000). In our study, we found homologous $y k k C$ and $y k k D$ genes in both sensitive (BT-0505) and resistant strains (TX-0702) (Supplementary Table S5), whereas amino acid sequence is identical in each gene in two strains, showed $<35 \%$ identity compared with the reported $y k k C$ and $y k k D$ genes in the CARD. In our study, we found homologous $y k k C$ and $y k k D$ genes in both sensitive (BT-0505) and resistant strains (TX-0702) (Supplementary Table S5), whereas amino acid sequence is identical in each gene in two strains, but the amino acid identity of these two genes is $<35 \%$ compared with the reported $y k k C$ and $y k k D$ genes in the CARD. Identical alleles are present in both resistant and susceptible strains (Jia et al. 2017).

In strain TX-0702, transposon mutagenesis and targeted knockouts of gene 03055 or 03056 led to a loss of streptomycin resistance. The 03055 locus has weak similarity $(<20 \%$ amino acid identity) to a multidrug efflux pump gene $m d t C$ in the CARD that belongs to the resistance-nodulation-cell division family found in $E$. coli and some enterobacteria. The 03056 exhibits weak similarity $(<20 \%$ amino acid identity) to QnrB8, which is involved in quinolone resistance in E. coli (Cattoir et al. 2007; Nagakubo et al. 2002). In streptomycinresistant and -sensitive $C$. michiganensis, there are several genes related to quinolone resistance with high identity to reported genes ( $>50 \%$ amino acid identity) (Gartemann et al. 2008). We were not able restore the resistance by complementation of 03055 or 03056 in individual knockouts. This may be owing to the use of plasmids for complementation as opposed to chromosomal insertion, resulting in overexpression of each gene. Alternatively, other genes may be involved in streptomycin resistance, potentially because of the accumulation of SNPs induced by the stress of electroporation in strain TX-0702.

Although C. michiganensis resistance to streptomycin is not widespread, we should not ignore the possibility of spread owing to overuse of streptomycin. We identified three strains isolated in 2007 from Hebei Province in China exhibiting streptomycin resistance. It is possible that strong selective pressure because of streptomycin application in this province led to the emergence of streptomycin resistance. Additional studies investigating the origin of streptomycin resistance should be performed to identify genes associated with resistance, and these studies may help predict the efficacy of streptomycin application and can monitor potential resistance spread.

\section{LITERATURE CITED}

Bankevich, A., Nurk, S., Antipov, D., Gurevich, A. A., Dvorkin, M., Kulikov, A. S., Lesin, V. M., Nikolenko, S. I., Pham, S., and Prjibelski, A. D. 2012. SPAdes: A new genome assembly algorithm and its applications to singlecell sequencing. J. Comput. Biol. 19:455-477.

Cattoir, V., Poirel, L., Rotimi, V., Soussy, C. J., and Nordmann, P. 2007. Multiplex PCR for detection of plasmid-mediated quinolone resistance $q n r$ genes in ESBL-producing enterobacterial isolates. J. Antimicrob. Chemother. 60:394-397.

Chalupowicz, L., Barash, I., Reuven, M., Dror, O., Sharabani, G., Gartemann, K. H., Eichenlaub, R., Sessa, G., and Manulis-Sasson, S. 2017. Differential contribution of Clavibacter michiganensis ssp. michiganensis virulence factors to systemic and local infection in tomato. Mol. Plant Pathol. 18: 336-346.

Chang, R., Ries, S., and Pataky, J. 1992. Effects of temperature, plant age, inoculum concentration, and cultivar on the incubation period and severity of bacterial canker of tomato. Plant Dis. 76:1150-1155.
Chiou, C.-S., and Jones, A. 1995. Molecular analysis of high-level streptomycin resistance in Erwinia amylovora. Phytopathology 85:324-328.

Coaker, G. L., Willard, B., Kinter, M., Stockinger, E. J., and Francis, D. M. 2004. Proteomic analysis of resistance mediated by $R \mathrm{~cm} 2.0$ and $R \mathrm{~cm} 5.1$, two loci controlling resistance to bacterial canker of tomato. Mol. PlantMicrobe Interact. 17:1019-1028.

Crofton, J., and Mitchison, D. 1948. Streptomycin resistance in pulmonary tuberculosis. BMJ 2:1009-1015.

Davis, M. J., Gillaspie, A. G., Jr., Vidaver, A. K., and Harris, R. W. 1984. Clavibacter: A new genus containing some phytopathogenic coryneform bacteria, including Clavibacter xyli subsp. xyli sp. nov., subsp. nov. and Clavibacter xyli subsp. cynodontis subsp. nov., pathogens that cause ratoon stunting disease of sugarcane and bermudagrass stunting disease. Int. J. Syst. Evol. Microbiol. 34:107-117.

de León, L., Siverio, F., López, M. M., and Rodríguez, A. 2008. Comparative efficiency of chemical compounds for in vitro and in vivo activity against Clavibacter michiganensis subsp. michiganensis, the causal agent of tomato bacterial canker. Crop Prot. 27:1277-1283.

Fatmi, M., Schaad, N., and Bolkan, H. 1991. Seed treatments for eradicating Clavibacter michiganensis subsp. michiganensis from naturally infected tomato seeds. Plant Dis. 75:383-385.

Finken, M., Kirschner, P., Meier, A., Wrede, A., and Böttger, E. C. 1993. Molecular basis of streptomycin resistance in Mycobacterium tuberculosis: Alterations of the ribosomal protein S12 gene and point mutations within a functional 16S ribosomal RNA pseudoknot. Mol. Microbiol. 9:1239-1246.

Gartemann, K.-H., Abt, B., Bekel, T., Burger, A., Engemann, J., Flügel, M., Gaigalat, L., Goesmann, A., Gräfen, I., and Kalinowski, J. 2008. The genome sequence of the tomato-pathogenic actinomycete Clavibacter michiganensis subsp. michiganensis NCPPB382 reveals a large island involved in pathogenicity. J. Bacteriol. 190:2138-2149.

Gillespie, S. H. 2002. Evolution of drug resistance in Mycobacterium tuberculosis: Clinical and molecular perspective. Antimicrob. Agents Chemother. 46:267-274.

Gitaitis, R., Beaver, R., and Voloudakis, A. 1991. Detection of Clavibacter michiganensis subsp. michiganensis in symptomless tomato transplants. Plant Dis. 75:834-838.

Gitaitis, R., and Walcott, R. 2007. The epidemiology and management of seedborne bacterial diseases. Annu. Rev. Phytopathol. 45:371-397.

Gleason, M. L., Gitaitis, R. D., and Ricker, M. D. 1993. Recent progress in understanding and controlling bacterial canker of tomato in eastern North America. Plant Dis. 77:1069-1076.

Han, H. S., Koh, Y. J., Hur, J.-S., and Jung, J. S. 2004. Occurrence of the strAstrB streptomycin resistance genes in Pseudomonas species isolated from kiwifruit plants. J. Microbiol. 42:365-368.

Hausbeck, M., Bell, J., Medina-Mora, C., Podolsky, R., and Fulbright, D. 2000. Effect of bactericides on population sizes and spread of Clavibacter michiganensis subsp. michiganensis on tomatoes in the greenhouse and on disease development and crop yield in the field. Phytopathology 90: 38-44.

Jack, D. L., Storms, M. L., Tchieu, J. H., Paulsen, I. T., and Saier, M. H. 2000. A broad-specificity multidrug efflux pump requiring a pair of homologous SMR-type proteins. J. Bacteriol. 182:2311-2313.

Jia, B., Raphenya, A. R., Alcock, B., Waglechner, N., Guo, P., Tsang, K. K., Lago, B. A., Dave, B. M., Pereira, S., Sharma, A. N., Doshi, S., Courtot, M., Lo, R., Williams, L. E., Frye, J. G., Elsayegh, T., Sardar, D., Westman, E. L., Pawlowski, A. C., Johnson, T. A., Brinkman, F. S., Wright, G. D., and McArthur, A. G. 2017. CARD 2017: Expansion and model-centric curation of the comprehensive antibiotic resistance database. Nucleic Acids Res. 45:D566-D573.

Kaup, O., Gräfen, I., Zellermann, E.-M., Eichenlaub, R., and Gartemann, K.-H. 2005. Identification of a tomatinase in the tomato-pathogenic actinomycete Clavibacter michiganensis subsp. michiganensis NCPPB382. Mol. Plant-Microbe Interact. 18:1090-1098.

Kirchner, O., Gartemann, K.-H., Zellermann, E.-M., Eichenlaub, R., and Burger, A. 2001. A highly efficient transposon mutagenesis system for the tomato pathogen Clavibacter michiganensis subsp. michiganensis. Mol. Plant-Microbe Interact. 14:1312-1318.

Krzywinski, M., Schein, J., Birol, I., Connors, J., Gascoyne, R., Horsman, D., Jones, S. J., and Marra, M. A. 2009. Circos: An information aesthetic for comparative genomics. Genome Res. 19:1639-1645.

Laine, M. J., Nakhei, H., Dreier, J., Lehtilä, K., Meletzus, D., Eichenlaub, R., and Metzler, M. C. 1996. Stable transformation of the gram-positive phytopathogenic bacterium Clavibacter michiganensis subsp. sepedonicus with several cloning vectors. Appl. Environ. Microbiol. 62:1500-1506.

Leben, C., and Keitt, G. 1954. Antibiotics and plant disease, effects of antibiotics in control of plant diseases. J. Agric. Food Chem. 2:234-239.

Lelis, F. M. V., Czajkowski, R., de Souza, R. M., Ribeiro, D. H., and van der Wolf, J. M. 2014. Studies on the colonization of axenically grown tomato plants by a GFP-tagged strain of Clavibacter michiganensis subsp. michiganensis. Eur. J. Plant Pathol. 139:53-66. 
Li, X., Tambong, J., Yuan, K. X., Chen, W., Xu, H., Levesque, C. A., and De Boer, S. H. 2018. Re-classification of Clavibacter michiganensis subspecies on the basis of whole-genome and multi-locus sequence analyses. Int. J. Syst. Evol. Microbiol. 68:234-240.

Liu, Y.-G., and Chen, Y. 2007. High-efficiency thermal asymmetric interlaced PCR for amplification of unknown flanking sequences. Biotechniques 43: 649-656.

McManus, P. S., Stockwell, V. O., Sundin, G. W., and Jones, A. L. 2002. Antibiotic use in plant agriculture. Annu. Rev. Phytopathol. 40: 443-465.

Medina-Mora, C., Hausbeck, M., and Fulbright, D. 2001. Bird's eye lesions of tomato fruit produced by aerosol and direct application of Clavibacter michiganensis subsp. michiganensis. Plant Dis. 85:88-91.

Meier, A., Sander, P., Schaper, K., Scholz, M., and Böttger, E. 1996. Correlation of molecular resistance mechanisms and phenotypic resistance levels in streptomycin-resistant Mycobacterium tuberculosis. Antimicrob. Agents Chemother. 40:2452-2454.

Moller, W., Schroth, M., and Thomson, S. 1981. The scenario of fire blight and streptomycin resistance. Plant Dis. 65:563.

Munkvold, G. P. 2009. Seed pathology progress in academia and industry. Annu. Rev. Phytopathol. 47:285-311.

Nagakubo, S., Nishino, K., Hirata, T., and Yamaguchi, A. 2002. The putative response regulator BaeR stimulates multidrug resistance of Escherichia coli via a novel multidrug exporter system, MdtABC. J. Bacteriol. 184: 4161-4167.

Poysa, V. 1993. Evaluation of tomato breeding lines resistant to bacterial canker. Can. J. Plant Pathol. 15:301-304.

Sandbrink, J., Van Ooijen, J., Purimahua, C., Vrielink, M., Verkerk, R., Zabel, P., and Lindhout, P. 1995. Localization of genes for bacterial canker resistance in Lycopersicon peruvianum using RFLPs. Theor. Appl. Genet. 90: 444-450.

Schatz, A., Bugle, E., and Waksman, S. A. 1944. Streptomycin, a substance exhibiting antibiotic activity against gram-positive and gram-negative bacteria. Proc. Soc. Exp. Biol. Med. 55:66-69.

Schindelin, J., Arganda-Carreras, I., Frise, E., Kaynig, V., Longair, M., Pietzsch, T., Preibisch, S., Rueden, C., Saalfeld, S., Schmid, B., Tinevez, J.-Y., White, D. J., Hartenstein, V., Eliceiri, K., Tomancak, P., and Cardona, A. 2012. Fiji: An open-source platform for biological-image analysis. Nat. Methods 9:676-682.

Schroth, M. 1979. Streptomycin resistance in Erwinia amylovora. Phytopathology 69:565-568.

Seemann, T. 2014. Prokka: Rapid prokaryotic genome annotation. Bioinformatics 30:2068-2069.
Sen, Y., Feng, Z., Vandenbroucke, H., van der Wolf, J., Visser, R. G., and van Heusden, A. 2013. Screening for new sources of resistance to Clavibacter michiganensis subsp. michiganensis $(\mathrm{Cmm})$ in tomato. Euphytica 190:309-317.

Sen, Y., van der Wolf, J., Visser, R. G., and van Heusden, S. 2015. Bacterial canker of tomato: Current knowledge of detection, management, resistance, and interactions. Plant Dis. 99:4-13.

Shaw, K. J., Rather, P. N., Hare, R. S., and Miller, G. H. 1993. Molecular genetics of aminoglycoside resistance genes and familial relationship of the aminoglycoside-modifying enzyme. Microbiol. Rev. 57:138-163.

Sundin, G. W., and Bender, C. L. 1994. Relative fitness in vitro and in planta of Pseudomonas syringae strains containing copper and streptomycin resistance plasmids. Can. J. Microbiol. 40:279-285.

Sundin, G. W., and Wang, N. 2018. Antibiotic resistance in plant-pathogenic bacteria. Annu. Rev. Phytopathol. 56:161-180.

Tancos, M. A., Chalupowicz, L., Barash, I., Manulis-Sasson, S., and Smart, C. D. 2013. Tomato fruit and seed colonization by Clavibacter michiganensis subsp. michiganensis through external and internal routes. Appl Environ Microbiol. 79:6948-6957.

Valenzuela, M., Méndez, V., Montenegro, I., Besoain, X., and Seeger, M. 2019. Streptomycin resistance in Clavibacter michiganensis subsp. michiganensis strains from Chile is related to an rpsL gene mutation. Plant Pathol. 68:426-433. van Heusden, A., Koornneef, M., Voorrips, R., Brüggemann, W., Pet, G., Vrielink-van Ginkel, R., Chen, X., and Lindhout, P. 1999. Three QTLs from Lycopersicon peruvianum confer a high level of resistance to Clavibacter michiganensis ssp. michiganensis. Theor. Appl. Genet. 99:1068-1074.

Wang, N., Pierson, E. A., Setubal, J. C., Xu, J., Levy, J. G., Zhang, Y., Li, J., Rangel, L. T., and Martins, J., Jr. 2017. The Candidatus Liberibacter-host interface: Insights into pathogenesis mechanisms and disease control. Annu. Rev. Phytopathol. 55:451-482.

Werner, N., Fulbright, D., Podolsky, R., Bell, J., and Hausbeck, M. 2002. Limiting populations and spread of Clavibacter michiganensis subsp. michiganensis on seedling tomatoes in the greenhouse. Plant Dis. 86:535-542.

Wittmann, J., Brancato, C., Berendzen, K., and Dreiseikelmann, B. 2016. Development of a tomato plant resistant to Clavibacter michiganensis using the endolysin gene of bacteriophage CMP1 as a transgene. Plant Pathol. 65:496-502.

Xu, X., Miller, S. A., Baysal-Gurel, F., Gartemann, K. H., Eichenlaub, R., and Rajashekara, G. 2010. Bioluminescence imaging of Clavibacter michiganensis subsp. michiganensis infection of tomato seeds and plants. Appl. Environ. Microbiol. 76:3978-3988.

Zhang, Y., Chen, Y., Zhu, X., Xu, Y., Hou, Y., Gao, T., and Zhou, M. 2011. A molecular mechanism of resistance to streptomycin in Xanthomonas oryzae pv. oryzicola. Phytoparasitica 39:393-401. 